\title{
Study the Ultrasonic Assisted for Polymeric Nanocomposite
}

\author{
W.S. Mohamed ${ }^{* 1}$, R.A. Sobh ${ }^{1}$, H.E. Nasr ${ }^{1}$ and A. M. Eid ${ }^{2}$ \\ ${ }^{1}$ Polymers \& Pigments Dept., National Research Centre, and \\ ${ }^{2}$ Ultrasonic Dept., National Institute of Standards, Egypt.
}

\begin{abstract}
$\mathbf{U}$ LTRASONIC transmission is a clean, non-damaging technique for characterization of polymer emulsions and dispersion systems. Propagation of ultrasonic wave was examined utilizing pulse - echo method using $2 \mathrm{MHz}$ frequency and temperature $300^{\circ} \mathrm{K}$. Polymeric nanocomposites were prepared using different monomer composition ratios of methyl methacrylate (MMA) \& butylacrylate (BuA) monomers in presence of different concentrations of titanium dioxide $\left(\mathrm{TiO}_{2}\right)$ nanoparticles via emulsion polymerization technique using ultrasonic waves as initiation systems for different time intervals and characterized by (TGA), X-ray analysis (XRD) and particle size analy sis using transmission electron microscope (TEM). The obtained results showed that the particles of the prepared nanocomposite samples in the nano-sized diameter ranged between $46.5-71.5 \mathrm{~nm}$. The ultrasonic velocity, density and viscosity of the prepared nanocomposite samples were measured at various concentrations. From the data, ultrasonic factors such as ultrasonic attenuation $(\alpha)$, adiabatic compressibility $(\beta)$, acoustic impedance $(Z)$, and stiffness constant (c) have been predestined by standard relations. These results are interpreted in terms of molecular interaction between the components of the mixture. The variation of $\beta, Z, \tau, \alpha$ and $c$ with concentration have been studied. The results have been compared with those obtained from various theories and the results are analyzed and interpreted in terms of molecular interactions.
\end{abstract}

Keywords: MMA, BuA, Titanium dioxide, Ultrasonic, Nanocomposite.

The formation of high temperature active sites during the breaking down of cavitations bubbles in the chemical reaction is effected by ultrasonic waves. In a very short time, the bubbles breaking down led to the formation of a high pressure reached to $\sim 1000 \mathrm{~atm}$ and intense local heating reached to $\sim 5000 \mathrm{~K}$ via high temperature rate of change [1]. Emulsion polymerization of different monomers such as styrene, methyl methacrylate and butyl acrylate using the features exploiting of ultrasonic radiation to produce emulsion latex were studied. In the ultrasonic emulsion polymerization, the monomeric radicals are generated by the reaction between the monomers and hydrogen and hydroxyl radicals generated by radiations decomposing of water molecules. Monomeric radicals in the ultrasonic emulsion polymerization can also be formed by radiation decomposition of the evaporated monomers. The monomer droplets are

*Corresponding Author: E.mail: wsabry1976@yahoo.com

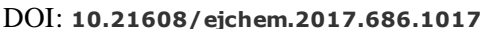

(C) 2017 The National Information \& Documentation Center (NIDOC) 
stabilized by diffusion of the former generated monomeric radicals into the surfactants producing polymer latex [2-10] .

Incorporation of inorganic nanoparticles into the ultrasonic emulsion latex are studied [11-15]. Many properties of the ultrasonic assisted emulsion polymers such as abrasion resistance, anticorrosion and thermal resistance are improved by inorganic nanoparticles incorporation [16-19]. The ultrasonic radiation enhances the inorganic homogenous dispersion of nanoparticles in polymer matrix, overcomes the polymer system destabilization, remove the agglomerations which may be formed due to inorganic nanoparticles addition [20]. Ultrasonic radiation also decreases the overall energy required for polymerization reaction and helps in controlling particle size distribution [21].

Titanium dioxide is utilized in various applications because it has a unique properties as bright appearance, high refractive index, among the highest available in nature [22], facilely obtained, cheap, not harmful and chemically stable. Due to these properties, titanium dioxide has various industrial application s where it can be used as a thickener in paints and coating materials, Furthermore, it is used as used a safe white pigment in textile and medicine products as well as its utilization in toothpaste[23].

Ultrasonic studies of various organic, inorganic and biological compounds in various solvents are very useful in explaining the intermolecular interactions between the constituents of molecules. Sound velocity is very susceptible to the component constituents in the sample where it is in relation to the attraction forces occurred between the medium constituents. The thermodynamic and a caustic parameters are determined by using the ultrasonic wave velocity as well as the sample viscosity.

The aim of this work is to investigate the advantages of ultrasound irradiation through the synthesis of polymeric nanocomposites consisting of (MMA/BuA) in combination with $\mathrm{TiO}_{2}$ nanoparticle and characterized via several characterization techniques as XRD, TEM, TGA and ultrasonic properties.

\section{Experimental}

\section{Materials}

The monomers methyl methacrylate (MMA) and butyl acrylate (BuA) were provided by Merck, Darmstadt, Germany. The monomers were redistilled and stored at $-20{ }^{\circ} \mathrm{C}$. Sodium dodecyl sulphate (SDS) was provided from Elnasr company (Egypt), Titanium (IV) oxide, a mixture of rutile and anatase nanopowder, $<100 \mathrm{~nm}$ particle size (BET), $99.5 \%$ trace metals basis obtained from Sigma-Aldrich- Germany. 


\section{Polymerization procedure [24]}

Polymeric nanocomposites were prepared using different composition ratios of MMA and $\mathrm{BuA}$ in the presence of different weights of $\mathrm{TiO}_{2}$ nanoparticles $(0.1,0.3$ and $0.5 \mathrm{gm}$.) using emulsion polymerization technique by irradiation ultrasonic initiation doses for different time intervals. The polymerization was carried out according to the following procedure: in a $250 \mathrm{ml}$ flask, $1 \mathrm{gm}$ of SDS was dissolved in distilled water $(90 \mathrm{ml}), 10 \mathrm{gm}$ of monomers mixture according to the selected BuA percentage (1, 3 and 5\%), were added and well irradiated using 400 watts ultrasonic irradiation as initiation system for different times $(5,10$ and 15 min). The nanocomposite samples preparation conditions are listed in Table 1.

TABLE 1. Preparation conditions of polymeric nanocomposites.

$\begin{array}{cccc}\text { Sample. No. } & \text { MMA/BuA ratio } & \text { TiO }_{2(\mathbf{g m})} & \text { Time(min.) } \\ \text { B1 } & 99 / 1 & 0.3 & 10 \\ \text { B2 } & 97 / 3 & 0.3 & 10 \\ \text { B3 } & 95 / 5 & 0.3 & 10 \\ \text { B4 } & 97 / 3 & 0.1 & 10 \\ \text { B2 } & 97 / 3 & 0.3 & 10 \\ \text { B5 } & 97 / 3 & 0.5 & 10 \\ \text { B6 } & 97 / 3 & 0.3 & 5 \\ \text { B2 } & 97 / 3 & 0.3 & 10 \\ \text { B7 } & 97 / 3 & 0.3 & 15\end{array}$

\section{Characterization}

Average particle size of the prepared emulsion lattices was determined by transmission electron microscope (TEM) using Zeiss, DSM 962 microscope (JEOL Co, Japan). The Thermogravimetric (TG) measurements for the prepared samples were carried out at a temperature range starting from $50^{\circ} \mathrm{C}$ to $700^{\circ} \mathrm{C}$ under a nitrogen atmosphere with the heating rate of $10^{\circ} \mathrm{C} / \mathrm{min}$ using Shimadzu TGA-50, Japan. X-ray diffraction for the prepared samples was investigated by X-ray diffraction by using Philips analytical X-ray.

\section{Ultrasonic measurements procedure}

The ultrasonic velocities in the liquid mixtures were measured using pulseecho method operating at a frequency of $2 \mathrm{MHz}$ (central frequency of $0.7 \mathrm{MHz}$ and bandwidth of $1.4 \mathrm{MHz}$ ). The uncertainty of the measurements is $\pm 10 \mathrm{~m} / \mathrm{sec}$. Using an oscilloscope (60 MHz time base oscilloscope, Philips, Netherlands) direct measurement of the time required for the pulses to travel twice the length of the specimen is possible, to allow immediate calculation of the ultrasonic wave velocity as given by the following equation :

$$
\mathrm{v}=\frac{\mathbf{z L}}{\Delta \mathrm{t}}
$$

where $\mathrm{L}$ is the liquid length and $\Delta \mathrm{t}$ is the time interval. The ultrasonic absorption coefficient $(\alpha)$ and ultrasonic viscosity $\left(\eta_{\mathrm{u}}\right)$ are given in the form; 


$$
\begin{aligned}
& \alpha=\frac{2 o}{2 \mathrm{~L}} \log \left(\frac{\mathrm{A}_{\mathrm{n}}}{\mathrm{A}_{\mathrm{n}+1}}\right) \\
& \mu_{\mathrm{u}}=\frac{\rho \alpha v^{3}}{26.3 \mathrm{f}^{2}}
\end{aligned}
$$

where $A_{n} / A_{n+1}$ is the ratio between two successive echoes $A_{n}, A_{n+1}, \rho$ is the density of the oil and (f) is the ultrasonic frequency. The uncertainty of the measurements of ultrasonic absorption and viscosity are $\pm 0.01 \mathrm{~dB} / \mathrm{cm}$ and \pm $0.03 \mathrm{mPa}$.s respectively. The experimental measurements were performed for all examined microemulsion samples having varied densities at ambient temperature $25^{\circ} \pm 1^{\circ} \mathrm{C}$. Each experiment was repeated three times and through three days consecutively, and the median was chosen as an end result.

\section{Results and Discussion}

\section{$X$-ray diffraction $(X R D)$}

The XRD patterns of the (MMA-BuA)/ $/ \mathrm{TiO}_{2}$ nanocomposites are shown in Fig. 1, 2 and 3. All Figures exhibit broad diffraction peaks of (MMA / BuA) / $\mathrm{TiO}_{2}$ nanocomposite at $2 \theta=15^{\circ}$, typical of an amorphous material, together with two lower intensities bands centered at $29^{\circ}$ and $40^{\circ}$.

Figure 1 illustrates the effect of $\mathrm{BuA}$ monomer percentage on the XRD patterns of the prepared nanocomposites. It is noticed that at low percentage of BuA (1\%) figure $1(\mathrm{a}-\mathrm{c})$ the peaks is at $14.7^{\circ}, 27.4^{\circ}$ and $41^{\circ}$ means there is an enhanced shift in the peaks and there are another low intensity broad peaks due to the anatase phase of $\mathrm{TiO}_{2}$ at $25.49^{\circ}$ another peak at $27.41^{\circ}$ due to formation of rutile $\mathrm{TiO}_{2}$ phase. As the concentration of BA increased to $3 \%$ wt the anatase phase vanished while there was reduce in the rutile phase intensity and this may be due to a decrease in crystallinty of the copolymer. By continue increasing the percentage of $\mathrm{BuA}$ to $5 \% \mathrm{wt}$, most of the titania is in anatase phase and the broadening of its peak tells that it is in the nano-scale.

Figure 2 describes the structure of the composite $(97 \% \mathrm{MMA} / 3 \% \mathrm{BuA}) / \mathrm{TiO}_{2}$ with changing the weight of the titania from 0.1 to $0.5 \mathrm{gm}$. Figure $2 \mathrm{a}$, shows that the copolymer with $0.1 \mathrm{gm}$ of titania, there is no distinct peaks mean that the composite is in amorphous state and by increasing the percentage of titania a low intense peak of rutile phase of titania appeared and at $0.5 \mathrm{gm}$ of titania (Fig .2 c), there is a higher intensity peaks appeared at $25.26^{\circ}$ with low intensity due to formation of anatase phase of titania and a high intensity peak at $27.38^{\circ}$ due to the rutile phase another peak appeared at $54.19^{\circ}$ and $68.83^{\circ}$ which mean that there is a small crystallinity phase is observed.

Figure 3(a-c), shows the effect of the time of exposure of the ultrasonic power on the $(97 \% \mathrm{MMA}-3 \% \mathrm{BuA}) / 0.3 \mathrm{TiO}_{2}$ nanocomposite. It is noticed that as the time increased from 5 to 15 min the peaks intensity is mostly unchanged

Egypt. J. Chem. 60, No.1 (2017) 
but it is wider with increasing the time and this show that as the time increases the particle size of the composite get smaller.

The polymer properties are considerably dependent on the percentage of the $\mathrm{TiO}_{2}$ nanoparticles, $\mathrm{BuA}$ monomer percentage and time of exposure of the ultrasonic wave's power. XRD is regularly used to detect the poly mer crystaillinity. It is clear that the crystallinity increases reaching the maximum value at $0.5 \mathrm{gm}$ of nano- $\mathrm{TiO}_{2}$, and this suggests changes in the regularity of polymeric chain structures. The oxygen from titanium dioxide was joined with $\mathrm{OH}$ groups from (PMMA-BuA) polymer chains. It is perceived that $\mathrm{TiO}_{2}$ plays an important influence in morphological and structural change in the polymer matrix [25].

\section{Physical parameters}

The data listed in Table 2 show the experimental measured values of ultrasonic velocity $(U)$ and density $(\rho)$ of the group samples with the calculated values of the elastic moduli. Figures 4, 5 and 6 show the relation between the density and ultrasound velocity with the group samples in the three systems listed in Table 1. The ultrasonic velocity decreased while the density is increased with increasing the concentration of $\mathrm{BuA}$ in the first system. On other hand ultrasonic velocity and the velocity increase as the density increase in the second system (with increasing the concentration of $\mathrm{TiO}_{2}$ ). Velocity and density have the same behavior in the third system with change of the time of exposure of the ultrasonic power. The velocity was $1657 \mathrm{~m} / \mathrm{s}$ at time $5 \mathrm{~min}, 1631 \mathrm{~m} / \mathrm{s}$ at $10 \mathrm{~min}$, then increased to be $1695 \mathrm{~m} / \mathrm{s}$ at $15 \mathrm{~min}$.

The ultrasonic velocity plays an important role in characterizing molecular rearrangement due to interactions exists between the component molecules in the mixtures. The decreasing in velocity indicate dispersion forces due to weak interactions where the increase in the velocity indicating strong interactions [25]

From Fig. 4, it has been observed that, the velocity is decreased in the BuA system suggests a role for dispersion forces in reaction system. Similar trends were also observed in the third system at 5 and 10 min exposure time but the velocity increased again at $15 \mathrm{~min}$ so we can conclude that at this time there is a strong intermolecular force between molecules. Also, the increasing in the intermolecular spacing in presence of $\mathrm{TiO}_{2}$ is due to decreasing in the velocity of ultrasonic wave [26] .

Chemical reactions via entire composition chains led to changing in ultrasonic velocity and this has been affirmed by presence of single $T_{g}$ for each studied constituent [27].

The obtained results may be due to the relationship between monomer and $\mathrm{TiO}_{2}$. Also, decreasing in ultrasonic velocity may be attributed to increasing of the free length $\mathrm{L}_{\mathrm{f}}$ and vice versa (i.e. the increase in the distances between 
molecular surfaces), also, the decrease in ultrasonic velocity indicate dispersion forces due to weak interactions as can be seen in Table 2 .
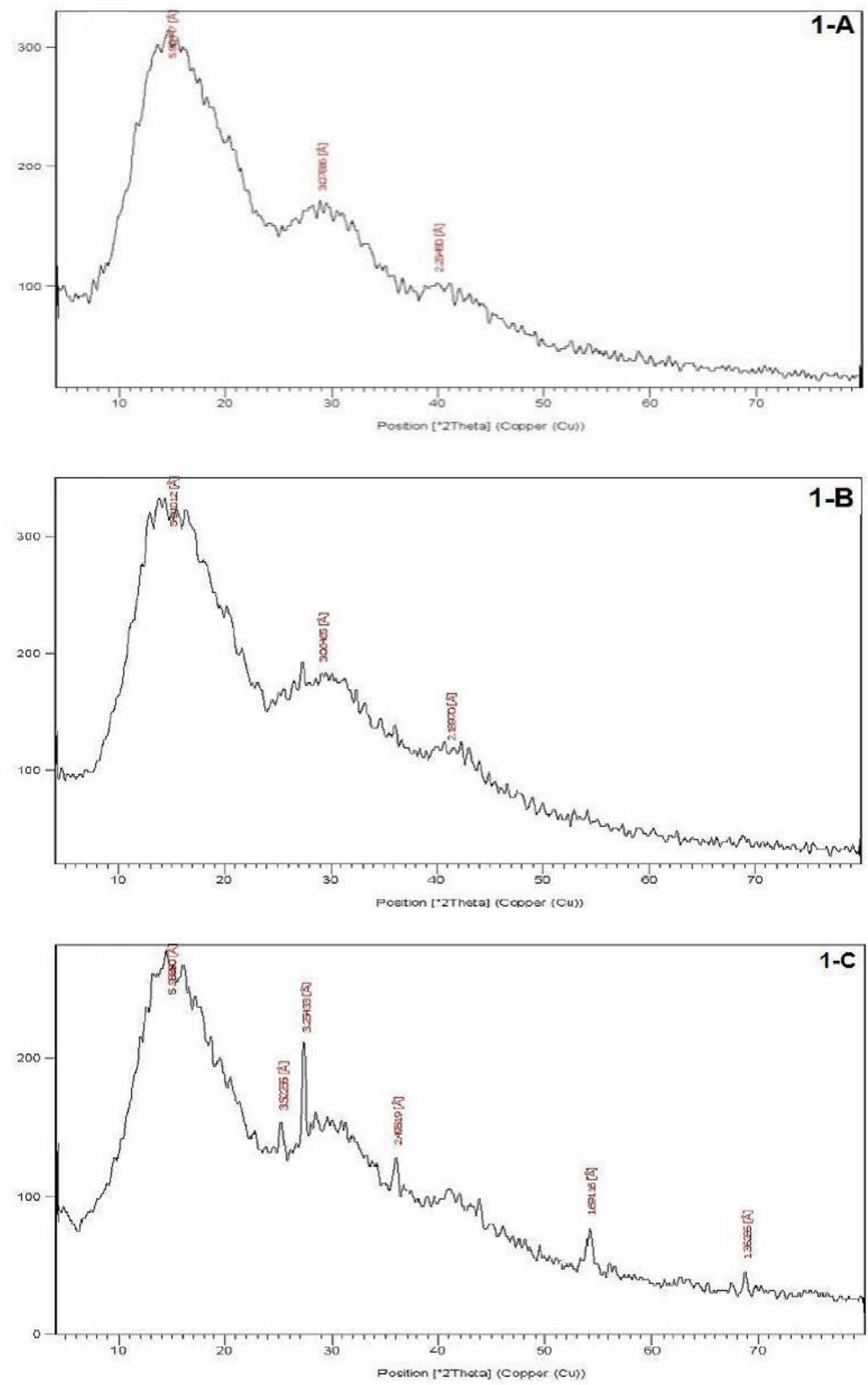

Fig. 1(a-c). XRD of the nanocomposites with a) $1 \%$, b) $3 \%$ \& c) $5 \%$ wt. $\%$ BuA.

Egypt. J. Chem. 60, No.1 (2017) 

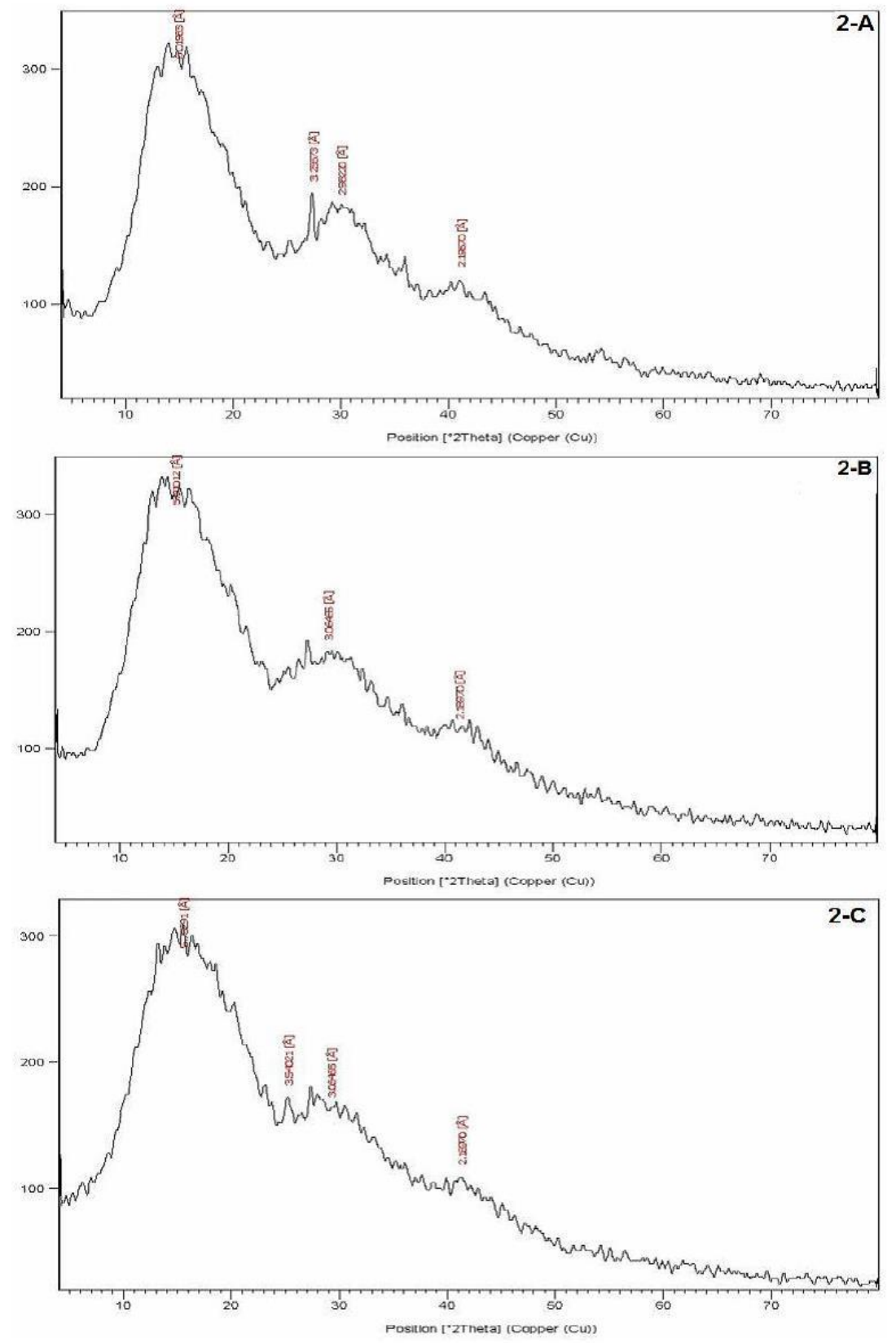

Fig. 2(a-c). XRD of the nanocomposites with a) 0.1 , b) $0.3 \&$ c) 0.5 gm. wt. $\mathrm{TiO}_{2}$.

Egypt. J. Chem. 60, No.1 (2017) 

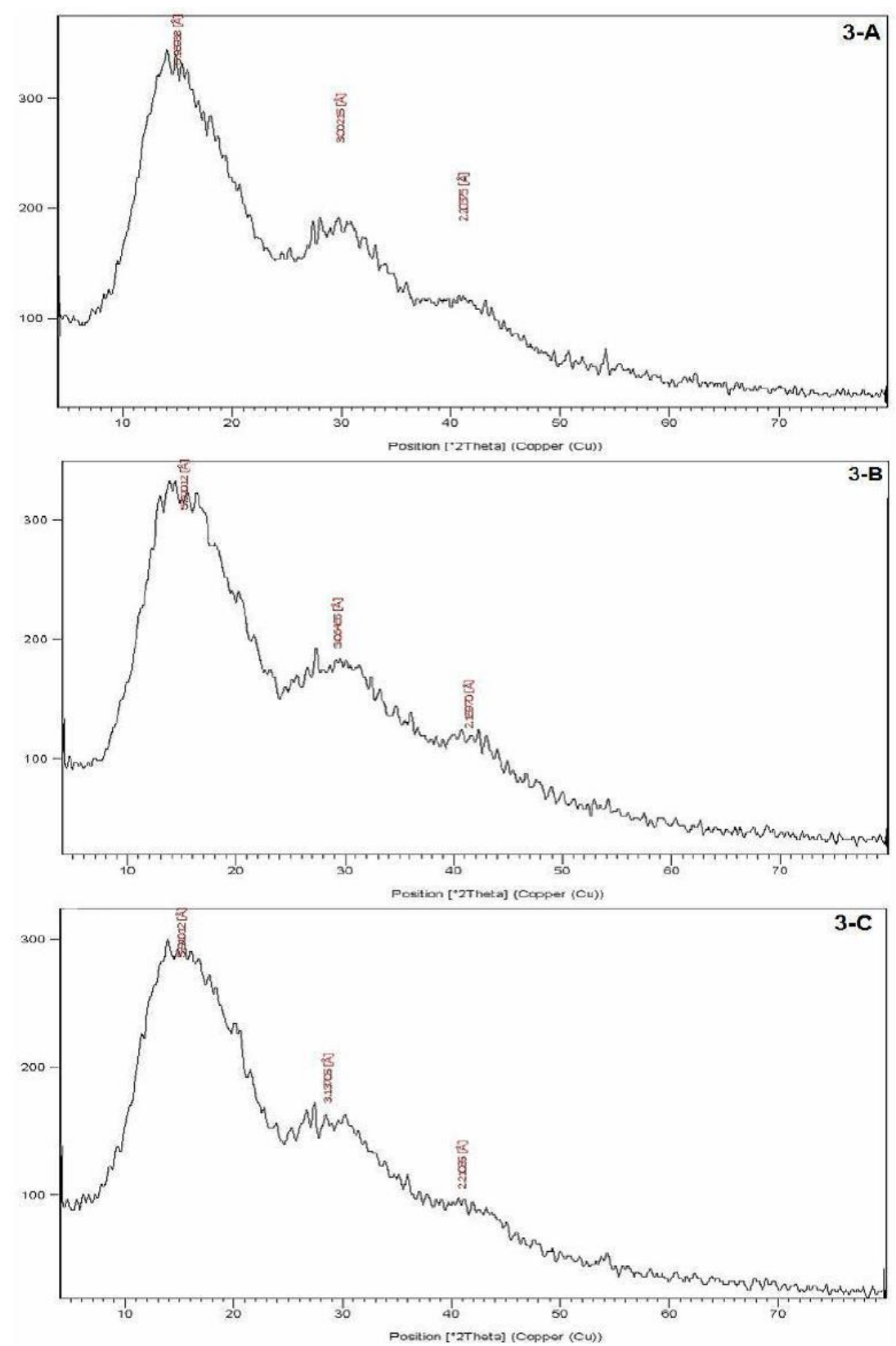

Fig. 3(a-c). XRD of the nanocomposites with a time of Ultrasonic power a) 5 , b) $10 \&$ c) $15 \mathrm{~min}$.

Egypt. J. Chem. 60, No.1 (2017) 
TABLE 2. The effect of BuA \%, TiO2 weight and ultrasonic time on the ultrasonic properties of the prepared samples.

\begin{tabular}{|c|c|c|c|c|c|c|c|c|c|}
\hline $\begin{array}{l}\text { Samp. } \\
\text { No. }\end{array}$ & B1 & B2 & B3 & B4 & B2 & B5 & B6 & B2 & B7 \\
\hline MMA & 99 & 97 & 95 & 97 & 97 & 97 & 97 & 79 & 97 \\
\hline $\mathrm{BuA}$ & $1 \%$ & $3 \%$ & $5 \%$ & $3 \%$ & $3 \%$ & $3 \%$ & $3 \%$ & $3 \%$ & $3 \%$ \\
\hline $\mathrm{TiO}_{2}$ & 0.3 & 0.3 & 0.3 & 0.1 & 0.3 & 0.5 & 0.3 & 0.3 & 0.3 \\
\hline Time $(\min )$ & 10 & 10 & 10 & 10 & 10 & 10 & 5 & 10 & 15 \\
\hline $\mathrm{V}_{\mathrm{m}}\left(\mathrm{cm}^{3}\right)$ & 10.09 & 10.2 & 10.44 & 10.4 & 10.2 & 10.08 & 10.18 & 10.2 & 9.97 \\
\hline$\rho\left(\mathrm{kg} / \mathrm{m}^{3}\right)$ & \multicolumn{3}{|c|}{1006.591020 .951021 .82} & \multicolumn{3}{|c|}{998.971020 .951035 .14} & \multicolumn{3}{|c|}{10231020.951044 .5} \\
\hline $\mathrm{v}_{\mathrm{L}}(\mathrm{m} / \mathrm{s})$ & 1660.4 & 1631 & 1620 & 1618 & 1631 & 1652 & 1657 & 1631 & 1695 \\
\hline$\alpha(\mathrm{dB} / \mathrm{cm})$ & 1.21 & 1.23 & 1.25 & 1.28 & 1.23 & 1.21 & 1.1 & 1.23 & 1.23 \\
\hline $\begin{array}{l}\text { Avg size } \\
(\mathrm{nm})\end{array}$ & 76 & 64 & 64 & 70 & 64 & 58 & 82 & 64 & 43.5 \\
\hline $\begin{array}{l}\beta_{\mathrm{a}} \times 10^{10} \\
\left(\mathrm{~m} \mathrm{~s}^{2} / \mathrm{kg}\right)\end{array}$ & 3.603 & 3.68 & 3.73 & 3.82 & 3.68 & 3.54 & 3.56 & 3.68 & 3.45 \\
\hline $\begin{array}{l}\mathrm{Z} \times 10^{6} \\
\left(\mathrm{~kg} \mathrm{~m}^{-2} \mathrm{~s}^{-1}\right)\end{array}$ & 1.67 & 1.66 & 1.65 & 1.62 & 1.66 & 1.71 & 1.69 & 1.66 & 1.74 \\
\hline $\begin{array}{l}\mathrm{L}_{\mathrm{f}} \times 10^{11} \\
(\mathrm{~m})\end{array}$ & 3.8 & 3.84 & 3.86 & 3.91 & 3.84 & 3.76 & 3.77 & 3.84 & 3.72 \\
\hline$\eta_{\mathrm{u}}(\mathrm{Pa} . \mathrm{s})$ & 5.29 & 5.18 & 5.14 & 5.14 & 5.18 & 5.38 & 4.88 & 5.18 & 5.64 \\
\hline
\end{tabular}

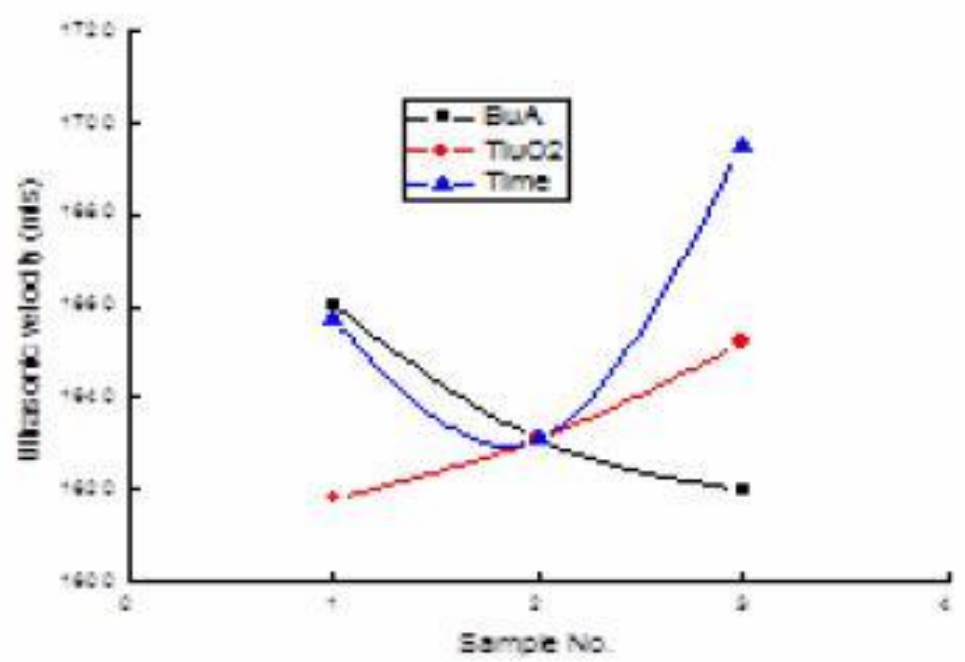

Fig. 4. Variation of the longitudinal ultrasonic velocity $\left(V_{1}\right)$ of the three nanocomposites systems having different composition ratios. 


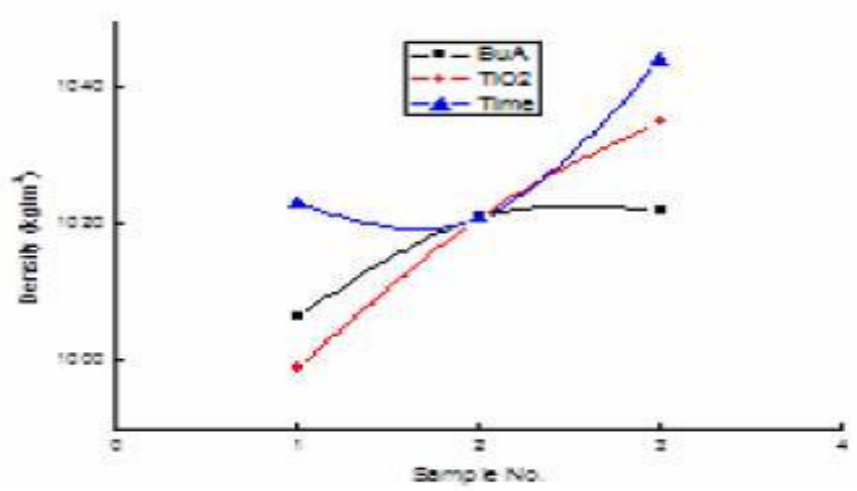

Fig. 5. Variation of the density ( $\rho$ ) of the three nanocomposites systems having different composition ratios.

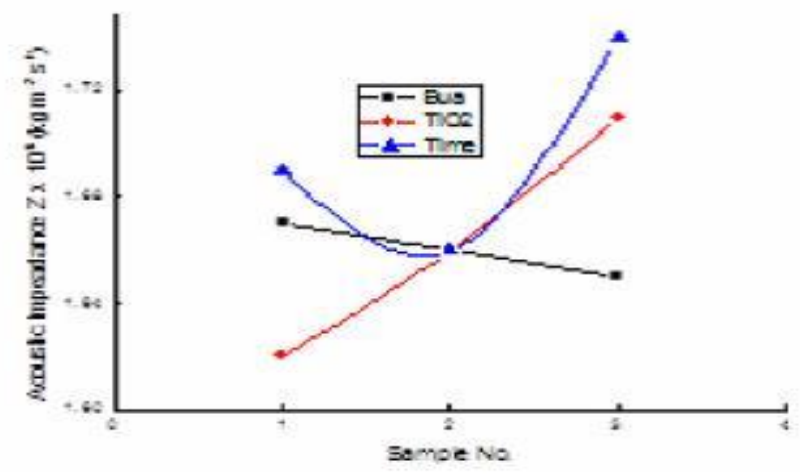

Fig. 6. Variation of acoustic impedance $(Z)$ of the three nanocomposites systems having different composition ratios.

The calculated value of the molar volumes $\left(\mathrm{V}_{\mathrm{m}}\right)$ is listed in Table 2 and Fig. 6 , and over the entire composition range.

Figure 7, illustrates the variation of molar volume with the concentration of $\mathrm{BuA}$, $\mathrm{TiO}_{2}$ and time of exposure to the ultrasonic power in the three studied factors at constant temperature. The change in the molar volumes that take place during mixing is the result of several effects that operate in the same or opposite directions $[28,29]$.

The three important different factors which may affect $V_{m}$ values are :

a) Scattering the liquid and negative side reactions between different molecules forming changing in $\mathrm{V}_{\mathrm{m}}$.

b) Variation in the volumes of molecules between liquid constituents.

c) The hydrogen bond formation between different molecules.

Egypt. J. Chem. 60, No.1 (2017) 


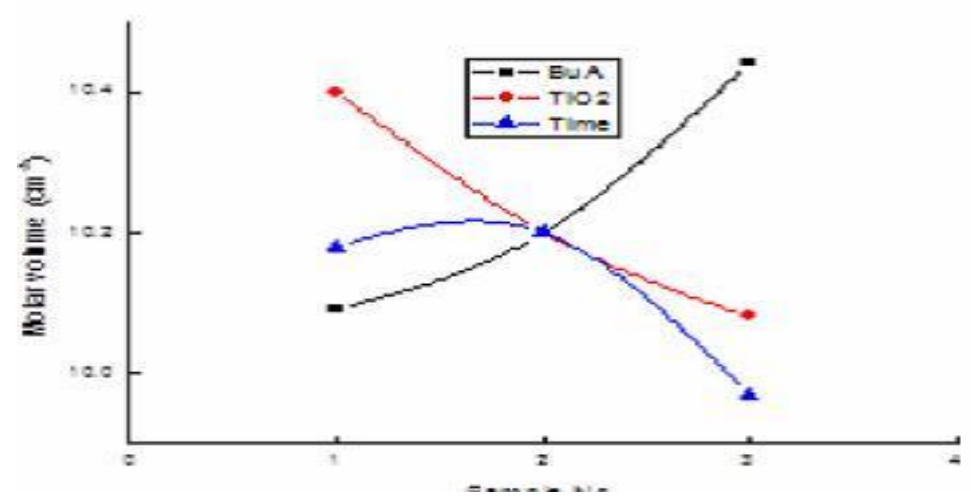

Fig. 7. Variation of molar volume $\left(V_{m}\right)$ of the three nanocomposite systems having different composition ratios.

The real volume change would, hence, rely on upon the strength of these contradicting factors.

In this study, the molar volume affected by :

(i) Decreasing in dipolar combination in acrylic ester compounds.

(ii) Feeble reactions between $\mathrm{TiO}_{2}$ and lone pair of electrons on acrylate group oxygen atom.

(iii) Interstitial accommodation of the smaller molecules upon voids formed by the larger molecules as a result of variation in molar volumes.

First and second factors increase the $\mathrm{V}_{\mathrm{m}}$ values. The third factor contributes to a contraction in volume. From figure 7 it is observed that the increase in $V_{m}$ values is found in the case of $\mathrm{BuA}$. The association between $\mathrm{TiO}_{2}$ molecules inhibited by the introduction of acrylic esters. The new hydrogen bond formation between $\mathrm{TiO}_{2}$ and carbonyl group oxygen atom of acrylic esters, this might be the reason for the observed decrease in $\mathrm{V}_{\mathrm{m}}$ in $\mathrm{TiO}_{2}$ system and in the third system with time of exposure. Finally, we conclude that weak specific interactions exist in $\mathrm{BuA}$ system and strong interactions present in $\mathrm{TiO}_{2}$ system.

The variations of $\beta_{\mathrm{a}}$ and $\mathrm{L}_{\mathrm{f}}$ with the $\mathrm{BuA}, \mathrm{TiO}_{2}$ and the time of exposure are shown in Table 2 and Fig. $8 \& 9$ over the studied composition range. The values of $\beta \mathrm{a}$ and $\mathrm{L}_{\mathrm{f}}$ are remarkably increased for $\mathrm{BuA}$ and nearly unchanged in the $\mathrm{TiO}_{2}$ system. In the third system with variation of time, the $\beta \mathrm{a}$ and $\mathrm{L}_{\mathrm{f}}$ are increased at $10 \mathrm{~min}$ then decrease at $15 \mathrm{~min}$. The values of $\beta \mathrm{a}$ and $\mathrm{L}_{\mathrm{f}}$ could be qualitatively investigated by considering the following factors which affect these functions. Generally, these functions rely on chemical, physical and structural contribution $[30,31]$. The physical contribution consists of dispersion forces or little dipoledipole interactions leads to increasing in $\beta \mathrm{a}$ and $\mathrm{L}_{\mathrm{f}}$ values. 

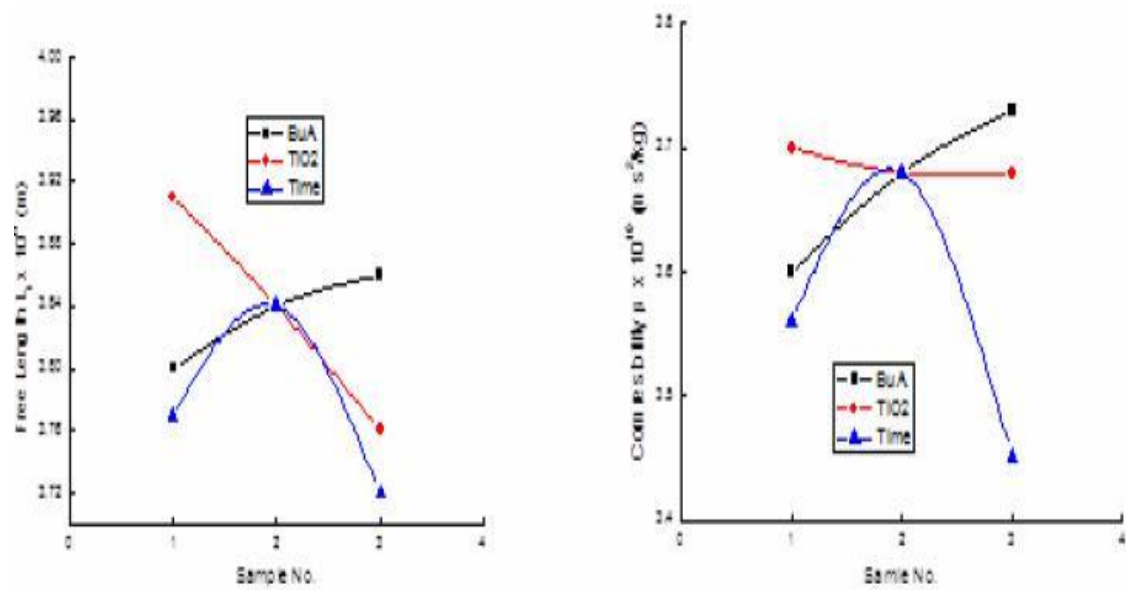

Fig. $8 \&$ 9. Variation of free length $\left(L_{f}\right)$ and adiabatic compressibility $\left(\beta_{a}\right)$ of the three nanocomposite systems having different composition ratios.

The aggregation formed by geometrical interference structure of two different size $\mathrm{TiO}_{2}$ molecules and hydrogen bond formation due to powerful dipole-dipole interaction led to decreasing in $\beta \mathrm{a}$ and $\mathrm{L}_{\mathrm{f}}$ values. While the components dissociation on the samples led to increasing in $\beta \mathrm{a}$ and $\mathrm{L}_{\mathrm{f}}$ values.

The ultrasonic attenuation coefficient $(\alpha)$ of studied samples was determined, listed in Table 2 and Fig. 10. For all studied samples, attenuation coefficient shows a little change regardless the measured values scattering due to instrumental error and ingrained difference in sample volume.

The change of the absorption coefficient of variation of $\mathrm{BuA}, \mathrm{TiO}_{2}$ and the time of exposure is due to elastic moduli and ultrasonic velocity alterations which have a relation with decreasing in free length $\mathrm{L}_{\mathrm{f}}$ and association of the acrylate molecules.

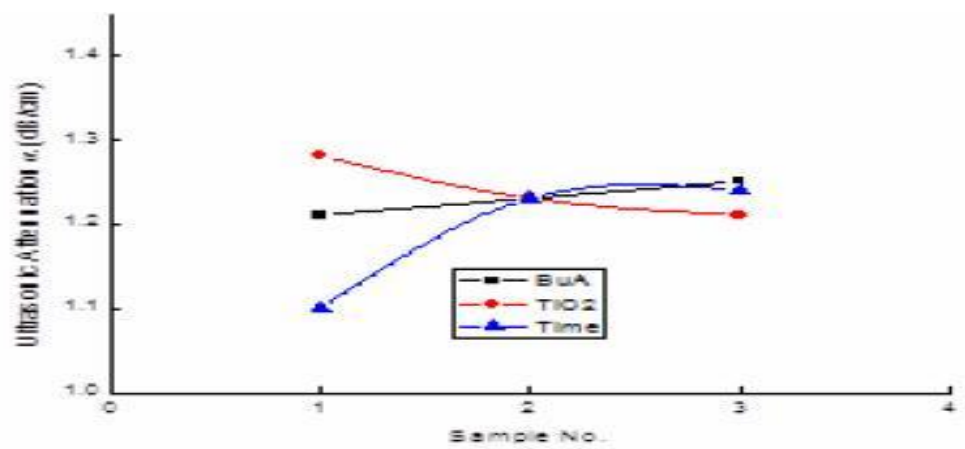

Fig. 10. Variation of ultrasonic attenuation $(\alpha)$ of the three nanocomposite systems having different composition ratios.

Egypt. J. Chem. 60, No.1 (2017) 
The data of the ultrasonic viscosity is given in Table 2 and illustrated in Fig. 11. The Viscosity coefficient decreased with increasing the BuA ratio in the prepared samples. This can attribute to the increase of the intermolecular spacing between molecules of $\mathrm{BuA}$ and the increase in free path length $\mathrm{L}_{\mathrm{f}}$. Deviation due to dynamically measurement for the viscosity including a noticeable displacement in the order of $\mu \mathrm{m}$ where the chains reiterate in the matrix. This may be due to; the ultrasonic wave is a little disorder with common extent in the scope of $\mathrm{A}^{\mathrm{o}}$. This can't make molecular dis sociation; subsequently viscosity identifies with little scale portability of short fragments among the molecules ${ }^{(32)}$.

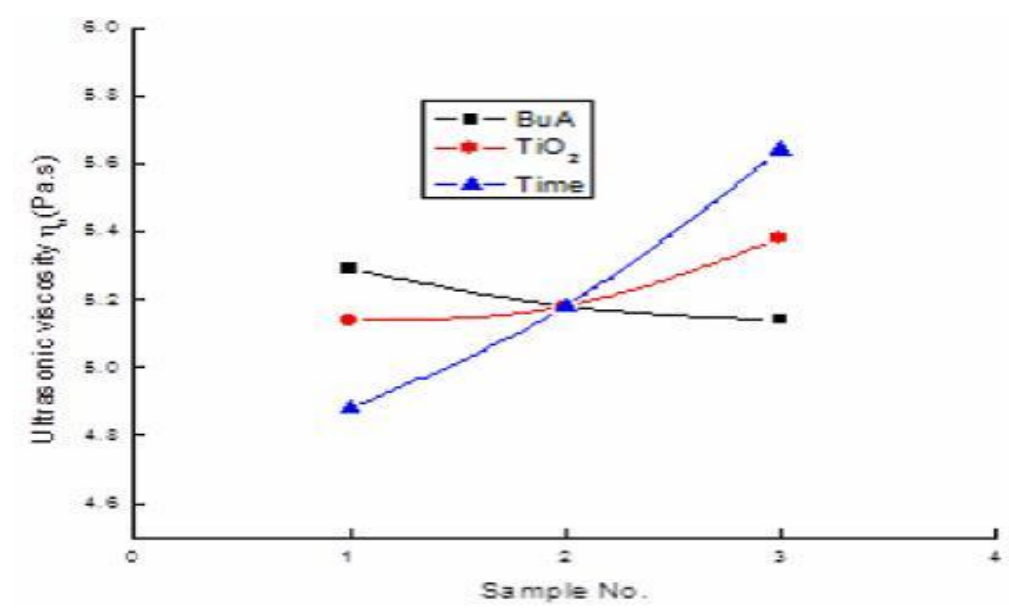

Fig. 11. Variation of ultrasonic viscosity $\left(\eta_{\mathrm{u}}\right)$ of the three nanocomposite systems having different composition ratios.

TEM Results (Morphological characterization).

Morphological characterization of the prepared (MMA/BuA) / $\mathrm{TiO}_{2}$ nanocomposite is shown in Fig. 12. The particle sizes of prepared samples are listed in Table 2. From Table 2, particle size decreases by increasing the $\mathrm{BuA} \%$ in the first group samples from $80 \mathrm{~nm}$ at $1 \% \mathrm{BuA}$ to $64 \mathrm{~nm} \mathrm{5 \%} \mathrm{BuA}$. Also the particle size decreased from $70 \mathrm{~nm}$ in case of $0.1 \mathrm{gm} \mathrm{Tio}_{2}$ to 64 and reaches to 58 $\mathrm{nm}$ for 0.3 and $0.5 \mathrm{gm}$ of $\mathrm{TiO}_{2}$ respectively. The effect of time is remarkable as the time of exposure of ultrasound radiation increased, the diameter of the particles decreased from $82 \mathrm{~nm}$ at $5 \mathrm{~min}$ to $43.5 \mathrm{~nm}$ at $15 \mathrm{~min}{ }^{(33)}$. 


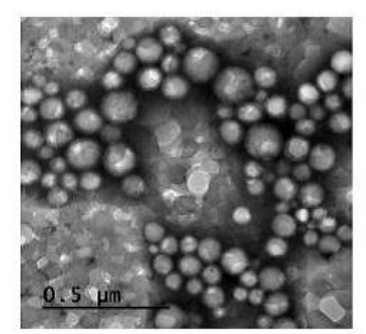

$\mathrm{BuA} 1 \%(70 \mathrm{~nm})$

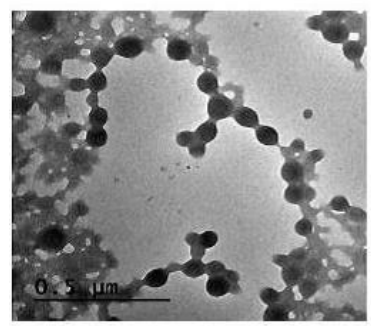

$\mathrm{TiO}_{2} \quad 0.1(70 \mathrm{~nm})$

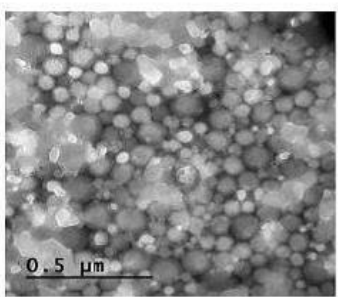

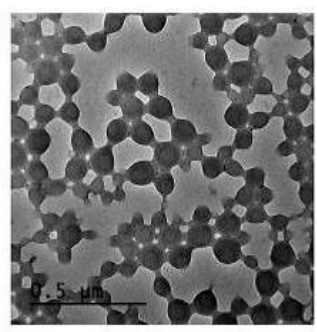

BuA 3\% (64 nm)

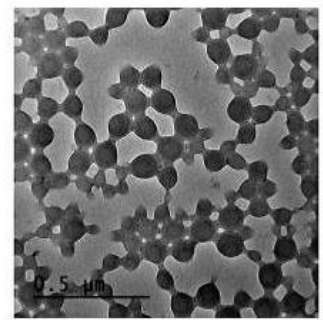

$\mathrm{TiO}_{2} \quad 0.3(64 \mathrm{~nm})$

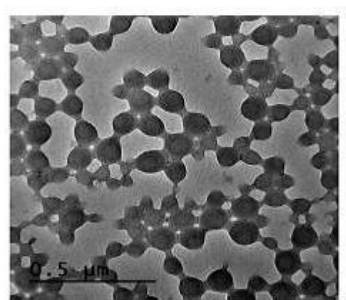

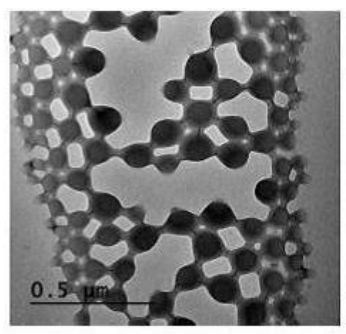

BuA $5 \%(64 \mathrm{~nm})$

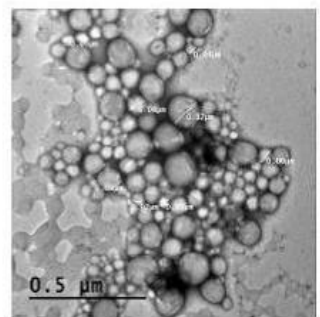

$\mathrm{TiO}_{2} \quad 0.5(58 \mathrm{~nm})$

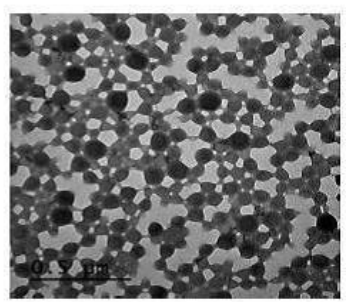

Fig. 12. TEM for the prepared nanocomposites.

\section{Thermal Gravimetric Analysis (TGA)}

TGA measurement is used to determine the effect of $\mathrm{BuA}$ monomer, $\mathrm{TiO}_{2}$ ratio and different ultrasonic irradiation time on thermal stability of prepared nanocomposites. This measurement was carried out within range 50:700 ${ }^{\circ} \mathrm{C}$. The TGA data are illustrated in Figs 13,14 \& 15 and listed in Table 3. From the data, it is obvious, at constant $\mathrm{TiO}_{2}(0.3 \mathrm{gm})$ and irradiation time (10 min), increasing of $\mathrm{BuA}$ monomer content plays an effective role in decreasing the thermal stability of the prepared nanocomposites. This is due to decreasing in homogenous dispersion between the individual layers. This leads to decreasing in thermal stability by increasing BuA monomer percentage ${ }^{(34)}$.

It is also clear that, at the same $\mathrm{BuA}$ monomer \% (3\%), and fixed ultrasonic irradiation time (10 $\mathrm{min})$, all weight lose temperatures increased with increasing the $\mathrm{TiO}_{2}$ ratio. this is due to limiting movement for organic chains attached to $\mathrm{TiO}_{2}$ nanoparticles ${ }^{(35)}$.

Egypt. J. Chem. 60, No.1 (2017) 
On the other hand, when the nanocomposites were prepared with the same $\mathrm{BuA}$ monomer $\%(3 \%)$ and constant $\mathrm{TiO} 2$ weight $(0.3 \mathrm{gm})$, with variable ultrasonic irradiation time, it is observed that, the increasing in the ultrasonic irradiation time led to increasing in the homogenous dispersion between the nanocomposite contents.

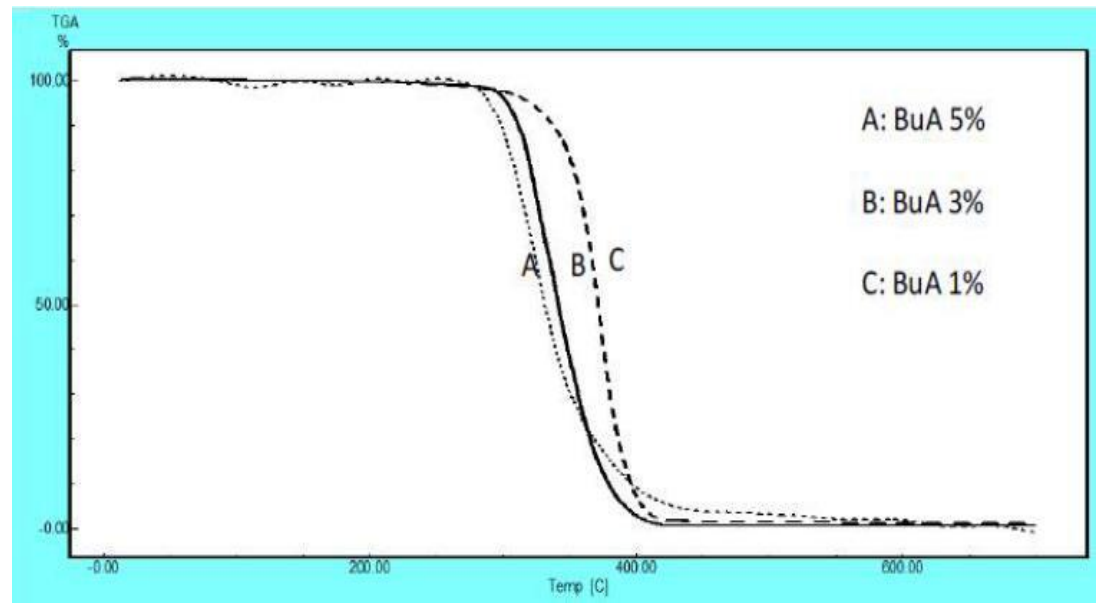

Fig.13. TGA thermograms of the prepared nanocomposites of different BuA \% .

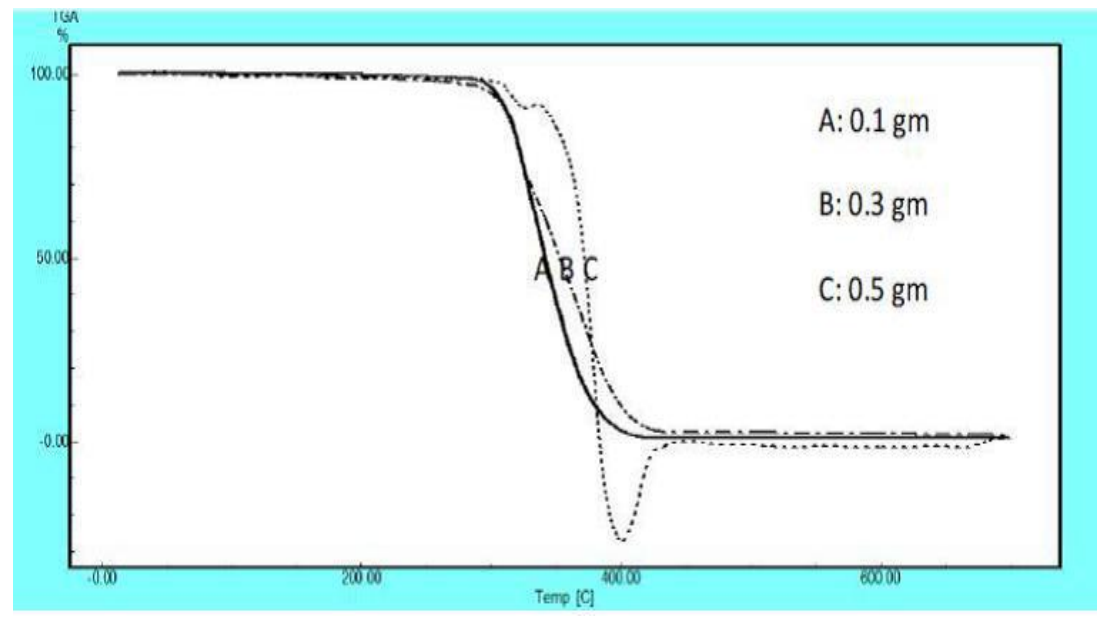

Fig. 14. TGA thermograms of the prepared nanocomposites of different $\mathrm{TiO}_{2}$ weight . 


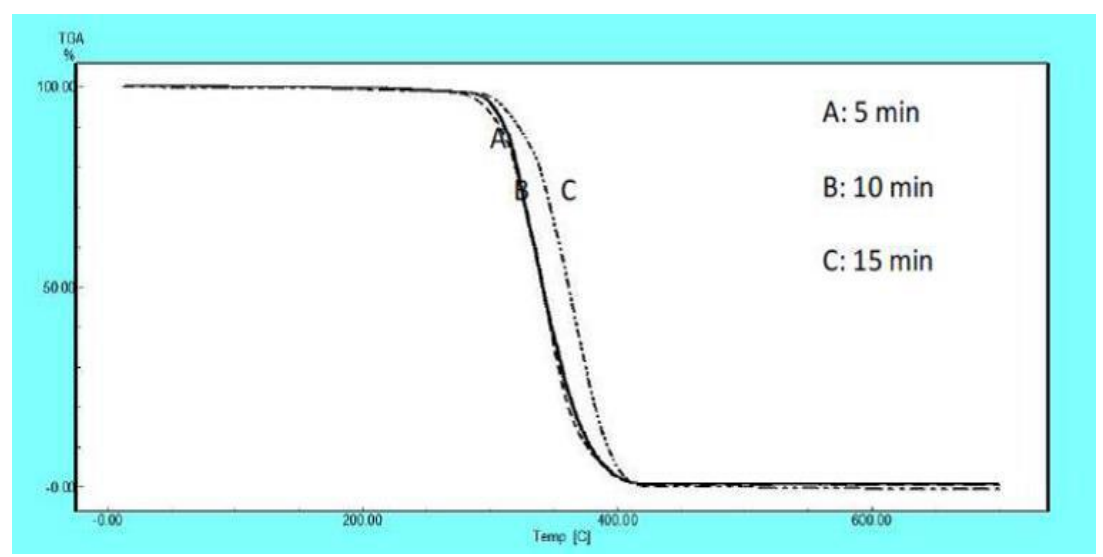

Fig. 15. TGA thermograms of the prepared nanocomposites of different irradiation ultrasonic time.

TABLE 3. TGA data obtained the prepared nanocomposites.

\begin{tabular}{|c|c|c|c|c|c|c|c|c|c|}
\hline \multirow{2}{*}{$\begin{array}{c}\text { Degradation } \\
\text { Temperature }\end{array}$} & \multicolumn{3}{|c|}{ Effect of BuA \% } & \multicolumn{3}{c|}{ Effect of TiO $\mathbf{2}_{2}$ weight } & \multicolumn{3}{|c|}{ Effect of ultrasonic time } \\
\cline { 2 - 11 } & $\mathbf{1 \%}$ & $\mathbf{3 \%}$ & $\mathbf{5 \%}$ & $\mathbf{0 . 1}$ & $\mathbf{0 . 3}$ & $\mathbf{0 . 5}$ & $\mathbf{5}$ min & $\mathbf{1 0}$ min & $\mathbf{1 5}$ min \\
\hline $\mathrm{T} 10$ & 335 & 309 & 297 & 308 & 309 & 328 & 305 & 309 & 327 \\
\hline $\mathrm{T} 25$ & 370 & 329 & 317 & 337 & 338 & 352 & 332 & 338 & 349 \\
\hline $\mathrm{Tdc}$ & 384 & 345 & 331 & 330 & 345 & 365 & 345 & 345 & 366 \\
\hline $\mathrm{T} 75$ & 396 & 353 & 352 & 341 & 353 & 355 & 350 & 353 & 380 \\
\hline
\end{tabular}

\section{Conclusion}

Polymeric nanocomposites using different monomer composition of methyl methacrylate (MMA) \& butyl acrylate (BuA) monomers in presence of different concentrations of titanium dioxide $\left(\mathrm{TiO}_{2}\right)$ nanoparticles via emulsion polymerization technique using ultrasonic waves as initiation systems for different time intervals were prepared and characterized by (TGA), X-ray analysis and particle size analysis using transmis sion electron microscope (TEM). The obtained results showed that the particles of the prepared nanocomposite samples in the nano-sized diameter ranged between $46.5-71.5 \mathrm{~nm}$.

From thermal gravimetric analysis, it was concluded that, All weight lose temperatures increased with increasing the $\mathrm{TiO}_{2}$ ratio, decreasing in thermal stability by increasing $\mathrm{BuA}$ monomer percentage and the increasing in the ultrasonic irradiation time led to increasing in the homogenous dispersion between the nanocomposite contents. 
The ultrasonic velocity decreased while the density is increased with increasing the concentration of $\mathrm{BuA}$, ultrasonic velocity and the velocity increase as the density increase (with increasing the concentration of $\mathrm{TiO}_{2}$ ).

Velocity and density have the same behavior with increasing the time of exposure of the ultrasonic power. The velocity was $1657 \mathrm{~m} / \mathrm{s}$ at time $5 \mathrm{~min}$, $1631 \mathrm{~m} / \mathrm{s}$ at 10 minutes, then increased to be $1695 \mathrm{~m} / \mathrm{s}$ at $15 \mathrm{~min}$.

\section{References}

1. Poddar M.K., Sharma S., and Moholkar, V.S., Investigations in two-step ultrasonic synthesis of PMMA/ZnO nanocomposites by in-situ emulsion polymerization Macromol. Symp. 361, 82 (2016).

2. Sharma, S., Poddar M.K. and Moholkar, M.S., Enhancement of thermal and mechanical properties of poly(MMA-co-BA)/Cloisite 30B nanocomposites by ultrasound-assisted in-situ emulsion polymerization, Ultrason. Sonochem. 36, 2102 (2017).

3. Kim, M.J., Jeon, I.Y., Seo, J.M., Dai, L. and Baek, J.B., Graphene Phosphonic Acid as an Efficient Flame Retardant ACS Nano 8 , 2820-2825 (2014).

4. Albano, C., Gonzalez, G. and Parra, C., Sonochemical synthesis of poly methy lmethacry late to be used as biomaterial. Polym. Bull 65, 893 (2010).

5. Zhu, H., Chen, D., Li, N., Xu, Q., Li, H., He, J. and Lu, J., A Robust and Cost-Effective Superhy drophobic Graphene Foam for Efficient Oil and Organic Solvent Recovery, Adv. Funct. Mater. 25, 597 (2015) .

6. Xin, G., Yao, T., Sun, H., Scott, S.M., Shao, D. and Wang, G., Highly thermally conductive and mechanically strong graphene fibers J. Lian, Science 349, 1083 (2015).

7. Wang, S., Ren, J., Li, W., Sun, R. and Liu, S., Properties of polyvinyl alcohol/xylan composite films with citric acid. Carbohydr. Polym. 103, 94 (2014).

8. Ojha, Mason, T.J., O'Donnell, C.P., Kerry, J.P. and Tiwari, B.K., Ultrasound technology for food fermentation applications Ultrason. Sonochem. 34,410 (2017).

9. Kojima,Y., Koda, S. and Nomura, H., Effect of ultrasonic frequency on polymerization of styrene under sonication. Ultrason. Sonochem. 8, 75 (2001).

10. Bhanvase, B.A. and Sonawane, S.H., New approach for simultaneous enhancement of anticorrosive and mechanical properties of coatings: Application of water repellent nano CaCO3-PANI emulsion nanocomposite in alkyd resin, Chem. Eng. J. 156, 177 (2010).

11. Bhanvase, B.A., Pinjari, D.V., Gogate, P.R., Sonawane, S.H., Pandit, A.B., Process intensification of encapsulation of functionalized $\mathrm{CaCO} 3$ nanoparticles using ultrasound assisted emulsion polymerization, Chem. Eng. Process. 50,1160 (2011).

12. Bhanvase, B.A., Pinjari, D.V., Gogate, P.R., Sonawane, S.H. and Pandit, A.B., Synthesis of exfoliated poly(styrene-comethylmethacrylate)/montmorillonite nanocomposite using ultrasound assisted in situ emulsion copolymerization, Chem. Eng. J. 181, 770 (2012). 
13. Shirsath, S.R., Hage, A.P., Zhou, M., Sonawane, S.H. and Ashokkumar, M., Ultrasound assisted preparation of nanoclay Bentonite-FeCo nanocomposite hybrid hydrogel: A potential responsive sorbent for removal of organic pollutant from water, Desalination 281, 429 (2011).

14. Barkade, S.S., Naik, J.B. and Sonawane, S.H., Ultrasound assisted miniemulsion synthesis of PANI/Ag ... for ethanol vapor sensing, Colloid and Surfaces, Colloid. Surf. A: Phy sicochem. Eng. Aspect. 378, 94 (2011).

15. D. Godshall, C. White and G. L., Effect of compatibilizer molecular weight and maleic anhydride content on interfacial adhesion of polypropylene-PA6 bicomponent fibers, J. Appl. Polym. Sci. 80, 1130 (2001).

16. Li, J., Li,Y., Niu , S. and $\mathbf{L i}, \mathbf{N}$., Ultrasonic-assisted synthesis of phosphorus graphene oxide/poly (vinyl alcohol) polymer and surface resistivity research of phosphorus graphene oxide/poly (vinyl alcohol) film, Ultrason. Sonochem. 36, 277 (2017)

17. Avella, M., Errico, M. and Martuscelli, E., Novel PMMA/CaCO3 nanocomposites abrasion resistant prepared by an in Situ polymerization process, Nano Lett. 1, 213 (2001).

18. Xie, X., Liu, Q., Li, R., Li, X., Li, Q., Zhang, Yu, Z. and Mai, Y., Rheological and mechanical properties of $\mathrm{PVC} / \mathrm{CaCO} 3$ nanocomposites preparaed by in situ poly merization, Polymer 45, 6665 (2004).

19. Chemat, F., Rombaut, N., Sicaire, A.G., Meullemiestre, A., Fabiano-Tixier, A.S. and Abert-Vian, M., A Ultrasound assisted extraction of food and natural products. Mechanisms, techniques, combinations, protocols and applications. A review. Ultrason. Sonochem. 34,540 (2017).

20. Brondnyan, J.G., Cala, J.A., Konen, T. and Kelley, E.L., Effect of Surfactant Concentration on Particle Nucleation in Emulsion Polymerization of $\mathrm{n}$-Butyl Methacrylate, J. Colloid Sci. 18, 73 (1963).

21. Mallakpour, S. and Jarahiyan, A., Utilization of ultrasonic irradiation as a green and effective strategy to prepare poly(N-vinyl-2-pyrrolidone)/modified nano-copper (II) oxide nanocomposites, Ultrason. Sonochem 37, 128 (2017).

22. Bhattacharjee, A. and Ahmaruzzaman, M., $\mathrm{CuO}$ nanostructures: facile synthesis and applications for enhanced photodegradation of organic compounds and reduction of $\mathrm{p}$-nitrophenol from aqueous phase. RSC Adv. 6, 41348 (2016).

23. Liao, Y., Wang, Q., Xia, H., Xu, X., Baxter, S.M., Slone, R.V., Wu, S., Swift, G. and Westmoreland, D.G., Preparation of Poly (n-butyl acrylates) Encapsulated Carbon Black via Ultrasonic Irradiation Initiating Emulsion Polymerization. J.Polym. Sci., Part A: Polym. Chem. 39, 3356 (2001).

24. Sobh, R.A., Mohamed, W.S., Mostafa, A.B. and Nasr, H.E., Encap sulation of curcumin and curcumin derivative in polymeric. Nanospheres, 54, 1457 (2015).

25. Mori, Y. and Saito, R., Synthesis of a poly(methyl methacrylate)/silica nanocomposite by soaking of a microphase separated polymer film into perhy dropoly silazane solution. Polymer, 45, 95-100 (2004).

26. Gaafar, M.E., EL-Sayad, E.A. and Marzouk, S.Y., Morphological, rheological and ultrasonic characterizations of ECO- friendly microemulsion latics based on acrylate monomers. Archives of Acoustics, 3 (3), 363-372 (2008). 
27. Peralta, R.D., Infante, R., Cortez, G., Cisneros, A. and Wisniak, J., Densities, excess volumes, and partial molar volumes of $m$-xylene, ethyl acrylate, butyl acrylate, methyl methacrylate, and styrene, Thermochim. Acta, 398, 39 (2003).

28. Mahendra Nath Roy, Anuradha Sinha and Biswajit Sinha, Excess molar volumes, viscosity deviations and isentropic compressibility of binary mixtures containing 1,3-dioxolane and monoalcohols at 303.15 K, J. Solution Chem., 34, 1311 (2005).

29. Suzan A. Ali and Mohamed, W. S., Kinetic and equilibrium studies of waste polyethylene doped nano-composite for dyestuff removal. Global J.Pure and Appl.Chem .Res.3,1,(2015).

30. Iloukhani, H. and Ghorbani, R.,Volumetric properties of N, Ndimethylformamide with 1,2-alkanediols at $20^{\circ} \mathrm{C}$, J. Solution Chem., 27, 141 (1998).

31. Assarson, P. and Eirich, F.R., Properties of amides in aqueous solution. I. Viscosity and density changes of amide-water systems. An analysis of volume deficiencies of mixtures based on molecular size differences (mixing of hard spheres). J. Phys. Chem., 72, 2710 (1968).

32. Srilalitha, S., Subha, M.C. and Chowdoji, R.K., Ultrasonic investigation of molecular interactions in binary mixtures at $303 \mathrm{~K}$. J. Pure Applied Ultrasonic, 18, 59 (1996).

33. Nasr, H.E. and Mohamed, W.S., In Situ emulsion polymerization of terpolymer / montmorillonite nanocomposites using redox initiation system. Journal of American Science, 6, 1196 (2010).

34. Mohamed, W.S., Nasr, H.E., Gutmann, R. and Sobh, R.A., Effect of $\mathrm{CaO}$ nanoparticles on the properties of polyamide 6. J. Egy. Chem. 58, 365 (2015).

35. Mohamed, W.S., Mostafa, A.B. and Nasr, H.E., Characterization and application of intercalated montmorillonite with verapamil and its polymethyl methacrylate nanocomposite in drug delivery. Polym. Plas. Tech. \& Eng. 53, 1425 (2014).

(Received 22/2/2017;

Accepted 6/3/2017 ) 


\section{دراسة مساعدة الموجات فوق الصوتية فى المتر اكبات البوليميرية النانومترية}

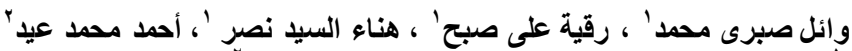

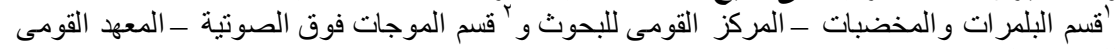

للقياس و المعايرة - مصر.

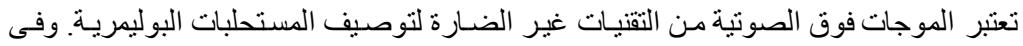

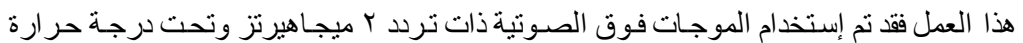

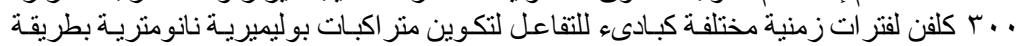

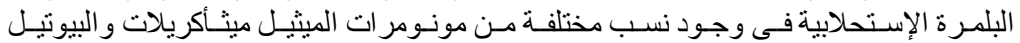

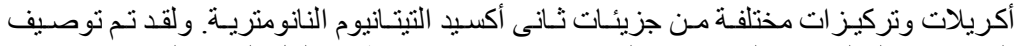

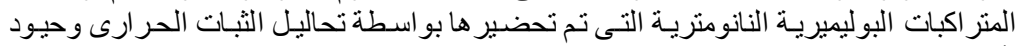

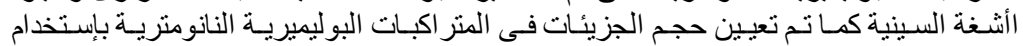

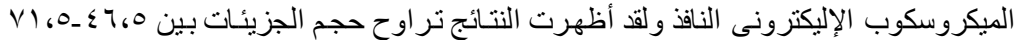

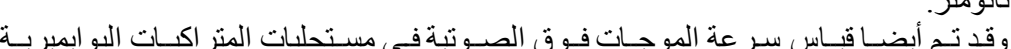

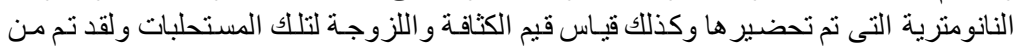

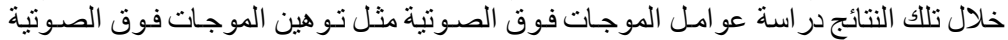

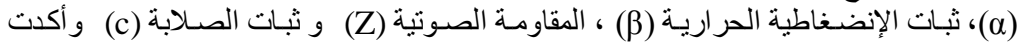
الدر اسة على وجود عو امل الموجات فوف الصونية في حالة قياسية. 